Open Access

\title{
Plasmadiafiltration ameliorating gut mucosal barrier dysfunction and improving survival in porcine sepsis models
}

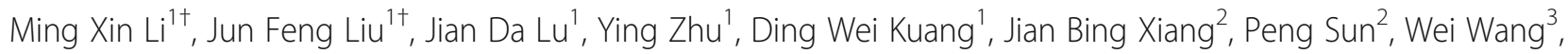
Jun Xue ${ }^{1 *}$, Yong $\mathrm{Gu}^{1}$ and Chuan Ming Hao ${ }^{1}$

\author{
* Correspondence: \\ xuejun@fudan.edu.cn \\ ${ }^{\dagger}$ Equal contributors \\ 'Department of Nephrology, \\ Huashan Hospital, Fudan University, \\ 12 Middle Wulumuqi Road, \\ Shanghai 200040, China \\ Full list of author information is \\ available at the end of the article
}

\begin{abstract}
Background: The object of this study is to explore whether the plasmadiafiltration (PDF) is more effective in improving the intestinal mucosal barrier function by removing more key large molecular inflammatory mediators and then prolonging the survival time.

Methods: Totally, 24 porcine sepsis models induced by cecal ligation and puncture (CLP) operation were randomly divided into three groups: PDF group, high-volume hemofiltration (HVHF) group, and control group, and received $8 \mathrm{~h}$ treatment, respectively. The expression of ZO-1 and occludin in intestinal mucosal epithelial cells were detected by immunohistochemistry, and apoptotic protein caspase-3positive lymphocytes were signed in mesenteric lymph nodes by TUNEL staining. The hemodynamic parameters were measured by invasive cavity detection. The tumor necrosis factor alpha (TNFa) and high-mobility group protein 1 (HMGB1) were tested by ELISA method. And then, the survival curves with all-cause death were compared with three groups.
\end{abstract}

Results: PDF led to a superior reversal of sepsis-related hemodynamic impairment and serum biochemistry abnormalities and resulted in longer survival time compared with HVHF and control $(p<0.01)$. Definitive protection from excessive TNF-a and HMGB1 response were only achieved by PDF. A more regular distribution pattern of ZO-1 and occludin along the epithelium was found in PDF animals $(p<0.01)$. The presence of apoptotic lymphocytes was significantly reduced in the PDF animals $(p<0.01)$.

Conclusions: PDF can effectively eliminate more pivotal inflammatory mediators of TNFa and HMGB1 and reduce the inflammation damage of the intestinal mucosal barrier and apoptosis of lymphocyte then improve the circulation function and prolong the survival time.

Keywords: Cecal ligation perforation (CLP), Sepsis, Plasmadiafiltration, Inflammatory mediators, Intestinal mucosal barrier

\section{Background}

During sepsis, the most frequent complication within the gastrointestinal tract is mucosal barrier dysfunction. Gut barrier lesion plays an important role in the pathophysiology of sepsis by promoting bacterial translocation [1, 2], which leads to secondary infection and multiple organ failure. The intestinal mucosal barrier consists of mechanical and 
immunological barrier. Unfortunately, the cascade of inflammation directly injuries intestinal epithelial tight junction permeability [3], particularly for tumor necrosis factor alpha (TNF $\alpha$ ) and high-mobility group protein 1 (HMGB1) [4], by impairing the function of mitochondria [5,6]. And meanwhile cytokine storm uptakes apoptosis of lymphocytes and intestinal epithelium cells via caspase active [7, 8]. Accordingly, epithelial dysfunction may be a common final pathway contributing to organ dysfunction in sepsis and other forms of critical illness. It plays a key role in the prognosis of sepsis and it should become the focus of the sepsis treatment.

The overall therapies and concept of blood purification have evolved toward nonspecifically removing a broad spectrum of plasma inflammatory mediators and also attenuating the tissue overwhelming systemic expression of pro- and anti-inflammatory mediators $[9,10]$. Rebuilding of immune homeostasis is thought to be able to improve outcomes and survival. Plasmadiafiltration (PDF), which used high cut-off hemofilter and diluted plasma as replacement fluid, represents new logical strategy to significantly increase middle- and high-molecule-weight mediator removal with low substitution flow rate. Compared to coupled plasma filtration and absorption or other plasmapheresis, PDF possesses better restoration of homeostasis and similar efficient cytokine clearance with simpler therapeutic modality. And meanwhile, a little fresh iced plasma complement essential coagulation factors and immunoglobulin that benefits sepsis recovery.

Our previous in vitro study [11] had demonstrated the safety and effectiveness of PDF for removing a sufficiently wide of inflammatory mediators and small molecular toxins from circulation, and it provided acceptable albumin depletion by a little plasma supplement.

This in vivo study was to explore whether PDF was more effective improving the intestinal mucosal barrier function by removing more key large molecular inflammatory mediators and then prolonging the survival time than that of classical hemofiltration.

\section{Methods}

\section{Anesthesia and surgical preparation}

The Animal Care Committee of the Fudan University approved the study. Twenty-four clean grade minipigs (body weight [BW] $36 \pm 1.3 \mathrm{~kg}$, aged $80 \pm 1.2$ days) were premedicated intramuscularly with ketamine $(10-15 \mathrm{mg} / \mathrm{kg}$ ) and diazepam $10 \mathrm{mg}$. Anesthesia ventilator (Matrx Model3000, USA) maintained with inhalation of mixture 1-5 \% isoflurane and oxygen by an endotracheal intubation. A catheter was inserted in the left carotid artery for blood pressure monitoring and blood sampling. Two 7 French SwanGanz flow-directed pacing catheters (131F7, $1.5 \mathrm{ml}$ CAP, Edwards, USA) were introduced aseptically via two 8 Fr. introducers (Exacta Percutaneous Sheath Inducer) into the right proximal and distal jugular veins, under continuous pressure monitoring, their tips were advanced into the pulmonary artery and right atrium, respectively. During anesthesia, the animals received continuous infusions with isotonic sodium chloride at $5 \mathrm{ml} / \mathrm{kg} / \mathrm{h}$. Baseline data were collected.

\section{CLP models}

CLP operation was performed with laparoscopic surgery (Olympus, Japan). Four incisions of $0.5-1.0 \mathrm{~cm}$ were made on the insufflated abdomen with carbon dioxide gas and trocars were placed through these incisions, then laparoscope and other instruments were 
introduced into the abdomen through these trocars. The cecum was identified and exposed and a specified $6 \mathrm{~cm}$ of the distal end of the cecum was ligated. Next, one incision of $1 \mathrm{~cm}$ at the free end of the cecum was made. The cecum was then gently compressed to extrude amount of cecal content. At last the instruments were pulled out and the abdominal skin incisions were closed. After resuscitation the porcines of CLP were backed animal room with free diet.

\section{Experiment protocol}

After $24 \mathrm{~h}$ of CLP operation, the experimental animals were induced with forward mentioned inhalation anesthesia and allocated into PDF, high-volume hemofiltration (HVHF) and control group in accordance with random digital generated by Stata 10.0 software (Stata Co. Ltd, USA). And the animals were then recannulated to begin the experimental period. The control group treated with hemoperfusion through an empty column with the same blood flow rate and anticoagulation method as that of the PDF and HVHF. All the animals received a continuous infusion of isotonic sodium chloride. The infusion rate was adjusted according to the clinical situation and to reach target central venous pressure of $5-10 \mathrm{cmH}_{2} \mathrm{O}$. After a maximal therapeutic and observation period of $32 \mathrm{~h}$, animals were lethally injected with potassium chloride.

\section{Plasmadiafiltration}

PDF therapies were delivered by the KM8900 machine (Quarary, Japan), and the EVAL membrane hollow fiber dialyzers were used, which had high cut-off of 60-70 KD (Evacure EC-2A, inside diameter $175 \mu \mathrm{m}$, wall thickness $40 \mu \mathrm{m}$, and effective surface area $1.0 \mathrm{~m}^{2}$, Sichuan Chemical Industry, Japan). Blood flow rate was set as $2.5 \mathrm{ml} / \mathrm{kg} / \mathrm{min}$ throughout the whole experiment while the replacing fluid that was consisted of commercially available substitution and plasma at the ratio of 3:1 was infused in a postdilution mode at the desired rate of $4 \mathrm{ml} / \mathrm{kg} / \mathrm{h}$ to maintain a zero fluid balance. Dialysate flow rate was set at $1000 \mathrm{ml} / \mathrm{h}$ consistently and net ultra filtration rate adjusted according to central venous pressure. For anticoagulation, porcines were given a loading dose of $6250 \mathrm{U}$ heparin, followed by a continuous infusion of $625 \mathrm{U} / \mathrm{h}$.

\section{High volume hemofiltration}

Zero-balanced hemofiltration was performed in a predilution mode with rate of $60 \mathrm{ml} / \mathrm{kg}$ / $\mathrm{h}$ using a polysulfone membrane (F60 HPS, an area of $1.3 \mathrm{~m}^{2}$, Fresenius, Germany) connected to a Diapact machine (B.Braun, Germany). Blood flow rate and anticoagulation method were designed as same as PDF treatment.

\section{Vital signs assessment, biochemistry data, and cytokine measurement}

Internal temperature, heart rate, respiratory rate, arterial blood pressure, blood oxygen saturation, cardiac output, pulmonary arterial wedge pressure, and central venous pressure were observed by multichannel physiological monitor (Agilent, Polymount GCX Corporation, USA) with different transducer connected to left carotid artery catheter and right jugular venous Swan-Ganz catheter respectively at 0, $24 \mathrm{~h}$, and then every $15 \mathrm{~min}$ after treatment. And urine volume per hour was documented with catheterization. 
Furthermore, blood sample were obtained for determination of leucocyte counts, serum sugar, creatinine, lactate, and blood gases at points 0 and $24 \mathrm{~h}$ and then every $2 \mathrm{~h}$ after treatment with COULTER LH750 (Beckman Coulter, USA) and ISTAT ${ }^{\oplus}$ Handheld (Abbott Point of Care, USA).

Serum samples were gathered at the same time point and stored in $-70{ }^{\circ} \mathrm{C}$ for later cytokines assay. The concentrations of HMGB1 and TNF- $\alpha$ trimer were detected by specific enzyme-linked immunosorbent assay (ELISA) kits, following the protocols of the manufacture (R\&D Systems Co., Minneapolis, MN).

\section{Immunohistochemistry of ZO-1 and occludin}

Immediately after death of CLP porcine, the $5 \mathrm{~cm}$ ileum section was obtained, and randomly sampled tissue blocks of approximately $50 \times 50 \times 50 \mu \mathrm{m}$ were fixed over night in $10 \%$ (wt/vol) PBS-buffered formaldehyde, following the protocols of the former paper described [12]. The positive areas were captured by Nikon System (Nikon NIS-Elements, Nikon Eclipse 50i H550S, DS-Fil, Nikon, Japan) and then immunochemistry index referred to the ratio of mean optical density/area was calculated with photo analysis software Image pro ${ }^{\circ}$ plus 6.0 (Media Cybernetics, USA). And all immunohistology data were quantitatively analyzed by Shanghai Showbio Biotechnology Company, as a blinded independent third-party testing agency.

\section{TUNEL assay for caspase-3-positive lymphocytes}

Mesenteric lymph nodes were obtained pre-CLP and at the moment of death, respectively, and were fixed as forward mentioned method. The terminal deoxynucleotidyl transferase mediated dUTP-biotin nick end labeling (TUNEL) assay was used to observe apoptotic lymphocytes in the mesenteric lymph node, following the protocols of the former paper described [12]. Brownish-yellow stained lymphocytes were an indication of positive cells. The apoptotic lymphocytes were identified and counted.

\section{Statistical methods}

All numerical data were expressed as mean \pm standard error. Normal distributed data with homogeneity or heterogeneity of variance was compared with Student's $t$ tests or Welch's $t$ test. And skewed distribution data was used Wilcoxon rank test. Multiple linear regressions were used to determine an association between cytokines and hemodynamic parameters. Survival times were calculated by Kaplan-Meier analysis and compared by the log-rank test. All analyses were performed by Stata software package 10.0 (StataCorp LP, College Station, TX, USA). A $p<0.05$ was considered to be of significant difference.

\section{Results}

\section{Clinic data and laboratory parameters}

All animals possessed the similar physiological attributes at baseline or after $24 \mathrm{~h}$ CLP operation between three groups (Table 1). And meanwhile, all CLP porcines conformed to sepsis shock diagnostic standard after $24 \mathrm{~h}$, according to the updated sepsis $3.0 \mathrm{cri}-$ teria [13], the occurrence of sepsis shock was assumed SOFA score $\geq 2$ (sequential 
Table 1 Comparison of hemodynamics and blood variables in three groups

\begin{tabular}{|c|c|c|c|c|c|c|c|}
\hline \multirow[t]{2}{*}{ Variable } & \multirow[t]{2}{*}{ Group } & \multicolumn{6}{|l|}{ Time (hour) } \\
\hline & & Baseline & 24 & 26 & 28 & 30 & 32 \\
\hline \multirow[t]{3}{*}{$\mathrm{PaO}^{2}(\mathrm{mmHg})$} & PDF & $108.9 \pm 20.1$ & $66.5 \pm 18.5 a^{a}$ & $74.50 \pm 5.79^{b}$ & $84.67 \pm 6.95^{b}$ & $93.00 \pm 5.18$ & $101.0 \pm 5.33$ \\
\hline & HVHF & $106.9 \pm 23.1$ & $65.8 \pm 19.8 a^{a}$ & $68.83 \pm 3.19$ & $74.17 \pm 3.26$ & $81.83 \pm 1.94$ & $89.50 \pm 4.76$ \\
\hline & Con. & $110.2 \pm 21.9$ & $68.0 \pm 16.9 a^{a}$ & $58.50 \pm 2.43$ & $54.67 \pm 2.73$ & $51.00 \pm 2.00$ & \\
\hline \multirow[t]{3}{*}{ MAP } & PDF & $77.7 \pm 2.07$ & $54.50 \pm 1.87^{\mathrm{a}}$ & $56.33 \pm 1.63$ & $58.33 \pm 1.63^{b}$ & $60.50 \pm 1.87$ & $62.50 \pm 1.87$ \\
\hline & $\mathrm{HVHF}$ & $79.2 \pm 1.93$ & $52.83 \pm 1.72^{a}$ & $51.83 \pm 1.33$ & $50.33 \pm 0.82$ & $50.67 \pm 1.75$ & $52.53 \pm 1.87$ \\
\hline & Con. & $76.9 \pm 1.89$ & $52.50 \pm 1.87^{\mathrm{a}}$ & $50.00 \pm 2.00$ & $47.33 \pm 2.25$ & $44.83 \pm 1.84$ & \\
\hline \multirow[t]{3}{*}{ PAWP } & PDF & $11.35 \pm 2.85$ & $22.00 \pm 3.74^{\mathrm{a}}$ & $19.67 \pm 2.58$ & $17.67 \pm 1.97^{b}$ & $16.17 \pm 1.47$ & $14.00 \pm 1.79$ \\
\hline & HVHF & $11.48 \pm 2.32$ & $23.00 \pm 3.74^{\mathrm{a}}$ & $22.33 \pm 3.27$ & $21.33 \pm 3.20$ & $20.50 \pm 3.08$ & $20.17 \pm 3.43$ \\
\hline & Con. & $12.01 \pm 3.07$ & $20.50 \pm 1.87^{\mathrm{a}}$ & $22.33 \pm 3.01$ & $24.00 \pm 3.63$ & $25.83 \pm 3.76$ & \\
\hline \multirow[t]{3}{*}{$\mathrm{CO}$} & PDF & $2.29 \pm 0.56$ & $2.12 \pm 0.25^{\mathrm{a}}$ & $2.10 \pm 0.26$ & $2.10 \pm 0.28^{b}$ & $2.18 \pm 0.27$ & $2.19 \pm 0.26$ \\
\hline & HVHF & $2.33 \pm 0.74$ & $2.19 \pm 0.27^{a}$ & $2.09 \pm 0.24$ & $1.98 \pm 0.22$ & $1.82 \pm 0.16$ & $1.71 \pm 0.17$ \\
\hline & Con. & $2.31 \pm 0.42$ & $2.18 \pm 0.28^{a}$ & $1.83 \pm 0.28$ & $1.53 \pm 0.15$ & $1.29 \pm 0.10$ & \\
\hline \multirow[t]{3}{*}{ Urine flow $(\mathrm{ml} / \mathrm{h})$} & PDF & $95.4 \pm 0.87$ & $18.33 \pm 1.63^{\mathrm{a}}$ & $20.00 \pm 1.41$ & $23.00 \pm 2.19^{b}$ & $26.17 \pm 2.40$ & $29.33 \pm 2.34$ \\
\hline & HVHF & $97.6 \pm 0.90$ & $20.00 \pm 2.61^{a}$ & $19.33 \pm 2.16$ & $18.67 \pm 2.42$ & $18.00 \pm 2.28$ & $17.50 \pm 2.88$ \\
\hline & Con. & $96.5 \pm 0.73$ & $20.67 \pm 2.42^{\mathrm{a}}$ & $15.67 \pm 3.78$ & $10.33 \pm 3.89$ & $6.17 \pm 4.54$ & \\
\hline \multirow[t]{3}{*}{ WBC $\left(\times 10^{9} / \mathrm{L}\right)$} & PDF & $13.8 \pm 4.3$ & $26.8 \pm 5.3 a^{a}$ & $25.8 \pm 4.9$ & $23.6 \pm 5.1$ & $22.7 \pm 4.5$ & $20.8 \pm 5.5$ \\
\hline & HVHF & $12.9 \pm 5.6$ & $27.7 \pm 5.9 a^{a}$ & $26.2 \pm 6.1$ & $24.5 \pm 3.9$ & $23.2 \pm 6.8$ & $21.9 \pm 7.5$ \\
\hline & Con. & $15.1 \pm 6.2$ & $23.4 \pm 4.2 \mathrm{a}^{\mathrm{a}}$ & $25.8 \pm 7.3$ & $24.4 \pm 4.2$ & $26.3 \pm 4.4$ & \\
\hline \multirow[t]{3}{*}{$\operatorname{Scr}(\mu \mathrm{mol} / \mathrm{l})$} & PDF & $83.5 \pm 15.3$ & $143.1 \pm 76.4^{\mathrm{a}}$ & $131.2 \pm 56.3$ & $127.4 \pm 26.8$ & $109.7 \pm 21.4$ & $97.62 \pm 23.5$ \\
\hline & HVHF & $85.8 \pm 12.5$ & $134.7 \pm 86.3^{\mathrm{a}}$ & $149.5 \pm 66.7$ & $142.3 \pm 45.2$ & $138.3 \pm 33.4$ & $120.5 \pm 32.8$ \\
\hline & Con. & $81.5 \pm 10.9$ & $140.3 \pm 80.4^{\mathrm{a}}$ & $155.9 \pm 67.3$ & $178.2 \pm 55.4$ & $195.8 \pm 32.1$ & \\
\hline \multirow[t]{3}{*}{$\mathrm{LAC}(\mathrm{mmol} / \mathrm{l})$} & PDF & $1.47 \pm 0.42$ & $4.28 \pm 1.40^{\mathrm{a}}$ & $3.26 \pm 1.12$ & $2.21 \pm 1.08^{b}$ & $1.97 \pm 0.76$ & $1.74 \pm 0.45$ \\
\hline & HVHF & $1.58 \pm 0.35$ & $4.32 \pm 1.18^{\mathrm{a}}$ & $3.47 \pm 1.16$ & $3.01 \pm 0.97$ & $2.14 \pm 0.65$ & $1.88 \pm 0.56$ \\
\hline & Con. & $1.35 \pm 0.52$ & $3.94 \pm 1.32^{\mathrm{a}}$ & $4.97 \pm 1.54$ & $5.87 \pm 1.17$ & $7.45 \pm 0.49$ & \\
\hline \multirow[t]{3}{*}{ Survival rate } & PDF & $8 / 8$ & $8 / 8$ & $8 / 8$ & $8 / 8$ & $7 / 8$ & $4 / 8$ \\
\hline & HVHF & $8 / 8$ & $8 / 8$ & $6 / 8$ & $4 / 8$ & $2 / 8$ & $2 / 8$ \\
\hline & Con. & $8 / 8$ & $8 / 8$ & $3 / 8$ & $2 / 8$ & $2 / 8$ & $0 / 8$ \\
\hline
\end{tabular}

PDF plasmadiafiltration, HVHF high-volume hemofiltration, Con. control, $\mathrm{PaO}^{2}$ partial pressure of blood oxygen, MAP mean arterial pressure, PAWP pulmonary artery wedge pressure, $C O$ cardiac output, WBC white blood cell, $S c r$ serum creatinine, LAC lactate

${ }^{a} p<0.01$ vs. the respective value at baseline

${ }^{b} p<0.01$ vs. the HVHF or control

organ function assessment (SOFA)) associated with at least two of the following signs: systolic blood pressure $\leq 100 \mathrm{mmHg}$ and serum lactate $\geq 2 \mathrm{mmol} / \mathrm{l}$.

After the onset of sepsis shock animals exhibited macrocirculatory derangement characterized by decreases in mean arterial pressure (MAP) and cardiac output (CO), and pulmonary disorders indicated by increase in pulmonary artery wedge pressure (PAWP) and decrease in partial pressure of blood oxygen $\left(\mathrm{PaO}_{2}\right)$, (Table 1$)$. PDF led to a distinctly superior reversal of sepsis-related hemodynamic impairment compared with HVHF and control. And meanwhile, the values of serum lactate, creatinine, and leucocyte were elevated after $24 \mathrm{~h}$ postinduction of CLP in all groups and much more normalized during the course of disease in PDF than in HVHF and control, only except leucocyte. This resulted in a definitive prevention of sepsis shock by PDF in a total of four porcines, two of which belonged to HVHF and no animals from control survived (see Fig. 1). 


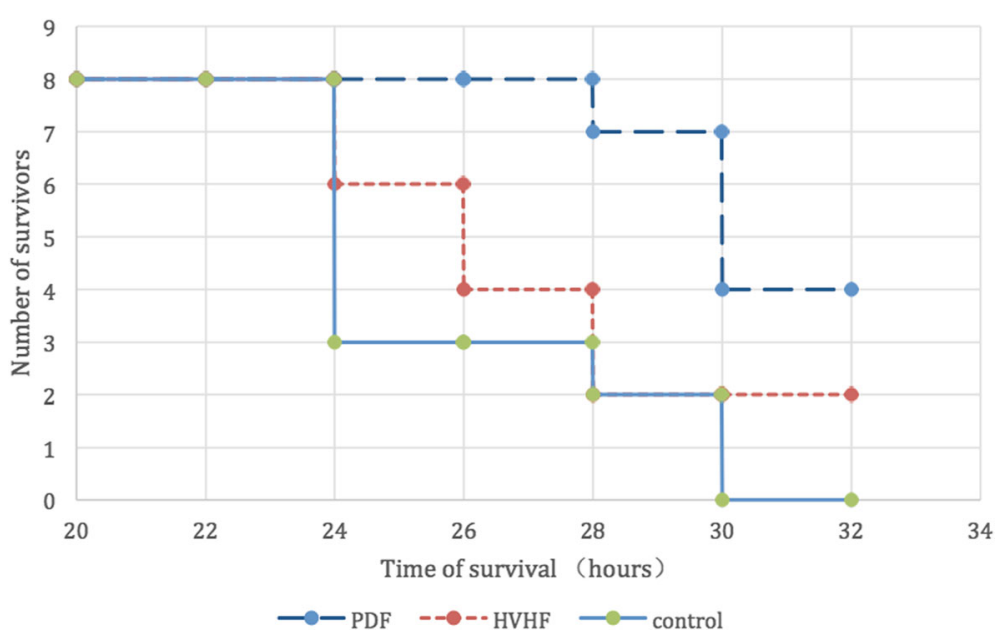

Fig. 1 Effects of extracorporeal blood purification on survival of cecal ligation puncture (CLP) porcine. Survival time (hours) was observed from the start of CLP. $p<0.01$, PDF Vs. HVHF or control group, respectively

\section{Changes of cytokines}

Differences in these circulating plasma cytokine concentrations for septic shock porcines therapy with PDF, HVHF, or control were shown in Fig. 2. Baseline or values of $24 \mathrm{~h}$ after CLP were not different among the three groups for any cytokine. However, CLP resulted in an increase of TNF- $\alpha$ and HMGB1 level. PDF more efficiently attenuated the TNF- $\alpha$ and HMGB1 level in serum (Fig. 2). And meanwhile, by multiple linear regressions analysis, only serum TNF- $\alpha$ level was significantly negative associated with MAP and CO, respectively $(p<0.05)$.

\section{Effects of sepsis on gut tight conjunction}

ZO-1 and occludin were measured by immunohistochemistry in ileum sections. Results indicate that, in the ileum tissues collected from CLP porcines, ZO-1 and occludin were comparatively continuously distributed along the epithelium in PDF group. In contrast, a significant disruption of immunosignal for them was observed along the epithelium in HVHF and control group, particularly for control animals, almost allnormal construction disappeared and infiltrated with a lot of inflammatory cells. (Fig. 3a, b)

\section{Numbers of apoptotic lymphocytes in the mesenteric lymph nodes}

Almost no apoptotic lymphocyte cells were detected in mesenteric lymph nodes at baseline (Fig. 4). At the endpoint of CLP induced sepsis shock, mesenteric lymph nodes from CLP animals demonstrated a marked appearance of dark brown apoptotic cells and intercellular apoptotic fragments (see arrow in Fig. 4). The presence of apoptotic cells or fragments was significantly reduced in the PDF animals (Fig. 4).

\section{Discussion}

Polymicrobial sepsis induced by cecal ligation and puncture (CLP) is the most frequently used model because it closely mimics the progression and attributes of human sepsis [14]. In addition, the higher the ligation and the bigger the incision size, the 


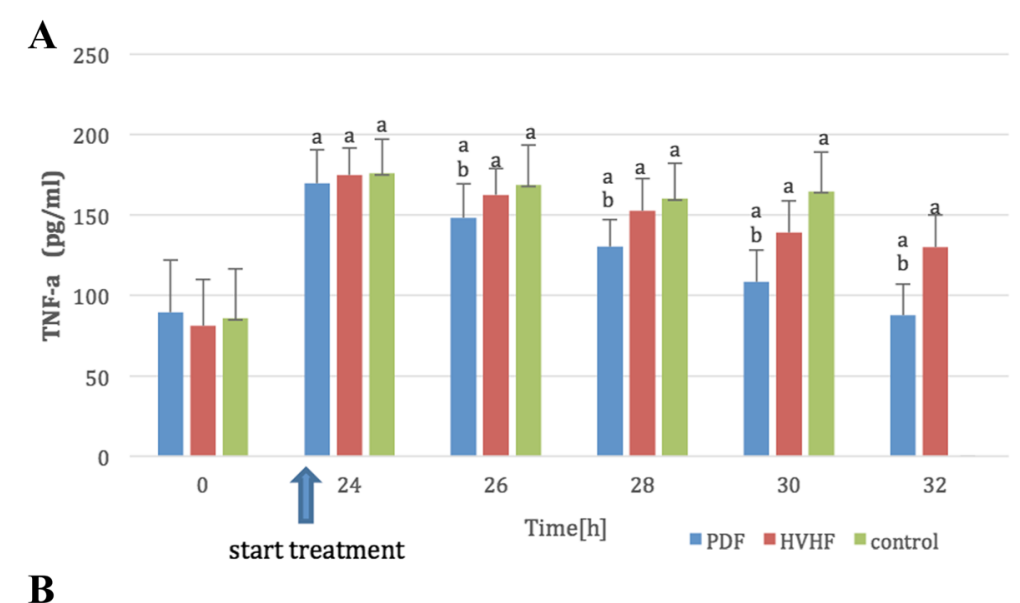

B

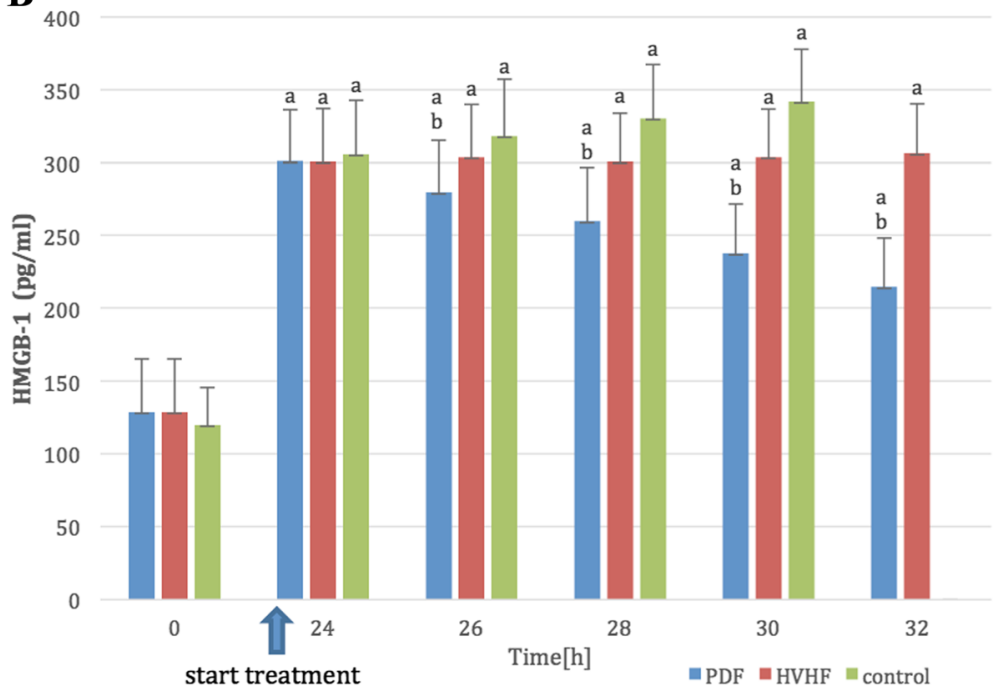

Fig. 2 Plasma tumor necrosis factor (TNF-a) (a) and high mobility group protein 1 (HMGB1) (b) levels obtained at different points of time. Definitive protection from overwhelming TNF-a and HMGB1 response were only achieved by plasmadiafiltration (PDF). Attenuation of cytokines was most effective in animals undergoing PDF. (a) $p<0.01$ vs. 0 h; (b) $p<0.01$ vs. HVHF or control, respectively

higher the mortality. Actually, most of sepsis-induced patients usually suffer from multiple organs dysfunction and sepsis shock in the clinic practice. Here, CLP with higher ligation and bigger incision successfully induced serious illness model that was full compliance with sepsis shock diagnostic standard after $24 \mathrm{~h}$, according to the updated sepsis 3.0 criteria [13], and which completely recreated human sepsis progression with similar hemodynamic and metabolic phases and the presence of both hyper- and hypoinflammatory phases, and also with prolonged and lower elevation of cytokine release, as in humans.

Recent technological progress has increased the number of techniques available for blood purification and their performance [15-17]. Unfortunately, recent a series of large multiple centers randomized controlled trials demonstrate that neither the different technique [18-20] nor the treatment dosage [21-24] had an impact on patient survival. Otherwise, PDF, the newer hybrid technique, which combines the hemodynamic and homeostasis stability of continuous renal replacement therapy with a more efficient depletion of broad spectrum of plasma inflammatory mediators and toxins similar to 


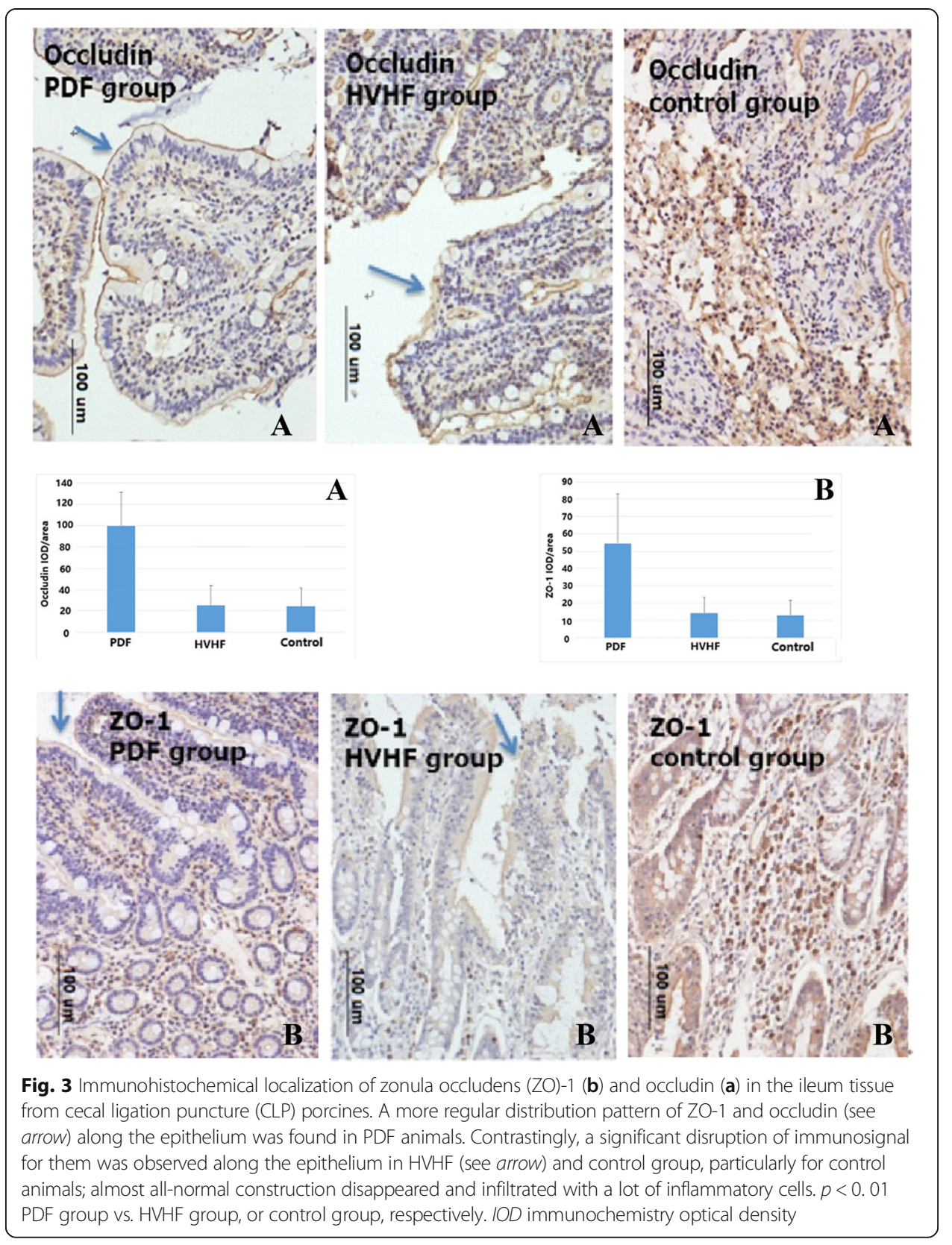

plasmapheresis, has been introduced as a new cost-effective simple approach to the treatment of acute kidney injury (AKI) in the sepsis shock. Our previous in vitro study [11] had demonstrated the safety and effectiveness of PDF for removing a sufficiently wide of inflammatory mediators and hypercatabolic toxins from circulation, and it provided acceptable albumin depletion by a little fresh iced plasma supplement that also benefited recovery of coagulation and immunity.

Delayed therapy was performed in this experiment protocol differentiated to previous animal research in order to preferably simulate the clinic practice. And the choice of $8 \mathrm{~h}$ treatment was supported from the results that daily hemodialysis or hemofiltration presented excellent detoxification with cardiovascular tolerability and similar outcomes [25-27], and meanwhile ameliorated anticoagulant dosage and disturbance of antibiotic concentration 


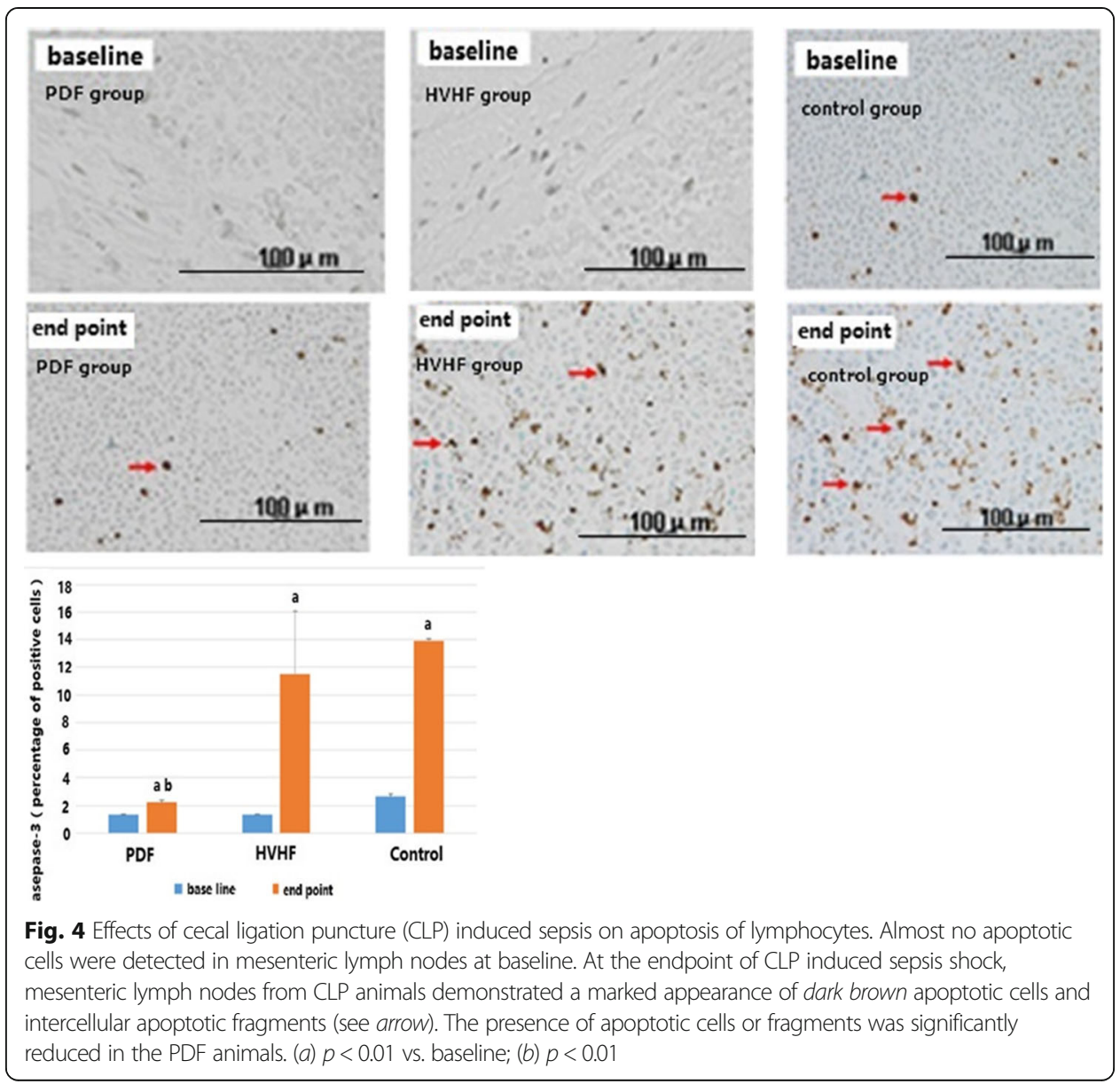

compared with continuous blood purification [28]. As expected result, PDF demonstrated significantly more effective prevention of sepsis-associated hemodynamic deterioration than HVHF and control. And meanwhile, the values of serum lactate, creatinine, and leucocyte were elevated after $24 \mathrm{~h}$ postinduction of CLP in all groups and much more normalized during the course of disease in PDF than in HVHF and control, only except leucocyte. This resulted in a definitive prevention of sepsis shock by PDF in a total of four porcines, two of which belonged to HVHF and no animals from control survived.

In our study, favorable clinical outcomes that were convincible elucidated that PDF with high cut-off (HCO) membrane was more efficient in regard to cytokine clearances, improved injury of gut tight junction and ameliorated apoptosis of lymphocytes. In animal models of sepsis, HCO membranes improve hemodynamics and prolong survival [29]. In patients with sepsis-related acute kidney injury, Morgera and colleagues [30] reported a significant higher clearance of cytokines and a reduction in vasopressor requirements with the use of $\mathrm{HCO}$ hemofiltration. In another randomized research, HCO hemofiltration restored the monocyte proliferation capacity of septic patients, probably by eliminating immunomodulatory mediators [31]. As is known, connective removal of a solute for high cut-off membrane depends on trans membrane pressure, which is conditioned by the rate of substitution, ultrafiltration, and dialysate. In order to achieve an acceptable balance between high cytokine and low albumin clearances, based on our former in vitro research result [11], we designed optimal combination of replacement, ultrafiltration, and dialysate 
as PDF protocol description. Although lessening a little bit inflammation factor clearance, it ensured enough cytokine removal and minimum albumin lost.

In inflammation, overproduction of TNF- $\alpha$ is pivotal in the induction of inflammatory genes, cell death, and in the recruitment and activation of immune cells [32]. In addition, it has been demonstrated that TNF- $\alpha$ plays a role in the control of epithelial permeability [33-35]. Moreover, TNF- $\alpha$ at higher concentrations leads to downregulation of ZO-1 protein expression and disturbance in junction localization of ZO-1 protein and functional opening of TJ barrier [12, 35, 36]. HMGB1, a potent late proinflammatory mediator in sepsis, also increased permeability of cultured epithelial monolayers in vitro and murine ileal mucosa in vivo [4]. Furthermore, a serious mechanism researches reveal inhibiting gut epithelial apoptosis by overexpression of $\mathrm{Bcl}-2$ was associated with a survival advantage in pseudomonas pneumonia-induced sepsis. This result suggested that intestinal epithelial apoptosis played a role in sepsis-related mortality [37]. And Dr. Julian's findings indicated that intestinal epithelium was more susceptible to mitochondrial damage and dysfunction than the lung epithelium in the context of sepsis [5]. Sepsis-induced inflammatory cells infiltration accompanied with cytokine releasing, epithelial apoptosis, and mitochondria dysfunction all involved in injury of gut tight junction [38, 39]. Therefore, intestinal failure is common in patients with septic shock, with dysfunction of the gut often manifesting as both a cause and consequence of their critical illness [40].

Actually, CLP resulted in an increase of TNF- $\alpha$ and HMGB1 level, a marked appearance of dark brown apoptotic lymphocyte cells, and a significant disruption of immunosignal for ZO-1 and occludin along the epithelium. It is very gratifying to see that PDF effectively attenuated the TNF- $\alpha$ and HMGB1 levels in serum (Fig. 2) and also improved apoptosis of lymphocyte and sepsis-related gut barrier injury.

\section{Conclusions}

PDF can effectively eliminate more large pivotal inflammatory mediators of TNF $\alpha$ and HMGB1 and improve the sepsis-related gut barrier dysfunction and apoptosis of lymphocyte, and meanwhile, it benefits the circulation function and prolong the survival time. In the future, large multicenter randomized controlled trials will further appraise the power of PDF therapies to reduce mortality or organ failure, rather than only concerning on cytokine clearance or transient improvement in physiologic variables.

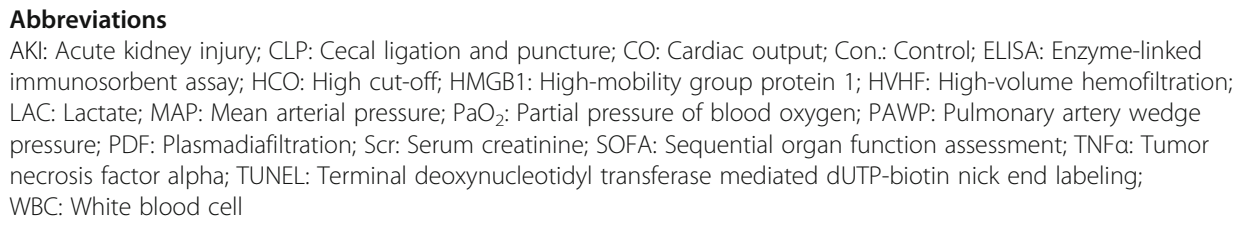

The project was supported by "National Nature Science Foundation of China" (No.30770541; No. 81271731). Sincerely thank Prof Yutaka Eguchi (Critical and Intensive Care Medicine, Shiga University of Medical Science, Seta Tsukinowa,

Ostsu, Shiga, Japan) for his continuous guidance during the whole study.

Funding

National Nature Science Foundation of China (No.30770541; No. 81271731). 
helped to operate with laparoscopy. WW administrated invasive hemodynamic measurement. JX conceived of the study, participated in its design and coordination and helped to draft the manuscript, and obtained funding. YG participated in the design of the study. CMH also participated in the design of the study. All authors read and approved the final manuscript.

\section{Competing interests}

The authors declare that they have no competing of interests.

\section{Author details}

'Department of Nephrology, Huashan Hospital, Fudan University, 12 Middle Wulumuqi Road, Shanghai 200040, China. ${ }^{2}$ Department of General Surgery, Huashan Hospital, Fudan University, 12 Middle Wulumuqi Road, Shanghai 200040, China. ${ }^{3}$ Department of Critical Care Medicine, Huashan Hospital, Fudan University, 12 Middle Wulumuqi Road, Shanghai 200040, China.

Received: 21 June 2016 Accepted: 20 September 2016

Published online: 29 September 2016

Reference

1. Levy MM, Fink MP, Marshall JC, Abraham E, Angus D, Cook D, Cohen J, Opal SM, Vincent JL, Ramsay G (2003) 2001 SCCM/ESICM/ACCP/ATS/SIS International Sepsis Definitions Conference. Intensive Care Med 29:530-538

2. Yu P, Martin CM (2000) Increased gut permeability and bacterial translocation in Pseudomonas pneumonias induced sepsis. Crit Care Med 28:2573-2577

3. Li Q, Zhang Q, Wang C, Liu X, Li N, Li J (2009) Disruption of tight junctions during polymicrobial sepsis in vivo. J Pathol 218:210-221

4. Yang R, Miki K, Oksala N, Nakao A, Lindgren L, Killeen ME, Mennander A, Fink MP, Tenhunen J (2009) Bile highmobility group box 1 contributes to gut barrier dysfunction in experimental endotoxemia. Am J Physiol Regul Integr Comp Physiol 297:R362-r369

5. Julian MW, Bao S, Knoell DL, Fahy RJ, Shao G, Crouser ED (2011) Intestinal epithelium is more susceptible to cytopathic injury and altered permeability than lung epithelium in the context of acute sepsis. In J Exp Path 92: 366-376

6. $\quad$ Singer M, Brealey D (1999) Mitochondrial dysfunction in sepsis. Biochem Soc Symp 66:149-166

7. Hotchkiss RS, Nicholson DW (2006) Apoptosis and caspases regulate death and inflammation in sepsis. Nat Rev Immunol 6:813-812

8. De Freitas I, Fernández-Somoza M, Essenfeld-Sekler E, Cardier JE (2004) Serum levels of the apoptosis associated molecules, tumor necrosis factor-alpha/tumor necrosis factor type I receptor and Fas/FasL in sepsis. Chest 125 2238-2246

9. Venkataraman R, Subramanian S, Kellum JA (2003) Clinical review: extracorporeal blood purification in severe sepsis. Crit Care 7:139-145

10. Kellum JA, Song M, Venkataraman R (2004) Hemoadsorption removes tumor necrosis factor, interleukin-6, and interleukin-10, reduces nuclear factor-kB DNA binding, and improves short-term survival in lethal endotoxemia. Crit Care Med 32:801-805

11. Li M, Xue J, Liu J, Kuang D, Gu Y, Lin S (2011) Efficacy of cytokine removal by plasmadiafiltration using a selective plasma separator: in vitro sepsis model. Ther Apher Dial 15:98-108

12. Mazzon E, Cuzzocrea S (2008) Role of TNF-a in ileum tight junction alteration in mouse model of restraint stress. Am J Physiol Gastrointest Liver Physiol 294:G1268-G1280

13. Seymour CW, Liu VX, Iwashyna TJ, Brunkhorst FM, Rea TD, Scherag A, Rubenfeld G, Kahn JM, Shankar-Hari M, Singer M, Deutschman CS, Escobar GJ, Angus DC (2016) Assessment of Clinical Criteria for Sepsis For the Third International Consensus Definitions for Sepsis and Septic Shock (Sepsis-3). JAMA 315:762-774

14. Dejager L, Pinheiro I, Dejonckheere E, Libert C (2011) Cecal ligation and puncture:the gold standard model for polymicrobial sepsis? Trends Microbiol 19:198-208

15. Peng Z, Singbartl K, Simon P, Rimmelé T, Bishop J, Clermont G, Kellum JA (2010) Blood purification in sepsis: a new paradigm. Contrib Nephrol 165:322-328

16. Call DR, Nemzek JA, Ebong SJ, Bolgos GL, Newcomb DE, Remick DG (2001) Ratio of local to systemic chemokine concentrations regulates neutrophil recruitment. Am J Pathol 158:715-721

17. Rimmelé T, Kellum JA (2011) Clinical review: Blood purification for sepsis. Crit Care 15:205-215

18. Lins RL, Elseviers MM, Van der Niepen P, Hoste E, Malbrain ML, Damas P, Devriendt J (2009) SHARF investigators: Intermittent versus continuous renal replacement therapy for acute kidney injury patients admitted to the intensive care unit: results of a randomized clinical trial. Nephrol Dial Transplant 24:512-518

19. Vinsonneau C, Camus C, Combes A, Costa de Beauregard MA, Klouche K, Boulain T, Pallot JL, Chiche JD, Taupin P, Landais P, Dhainaut JF (2006) Continuous venovenous haemodiafiltration versus intermittent haemodialysis for acute renal failure in patients with multiple-organ dysfunction syndrome: a multicentre randomised trial. Lancet 368:379-385

20. Wald R, Shariff SZ, Adhikari NK, Bagshaw SM, Burns KE, Friedrich JO, Garg AX, Harel Z, Kitchlu A, Ray JG (2014) The Association Between Renal Replacement Therapy Modality and Long-Term Outcomes Among Critically III Adults With Acute Kidney Injury: A Retrospective Cohort Study. Crit Care Med 42:868-877

21. Bellomo R, Cass A, Cole L, Finfer S, Gallagher M, Lo S, McArthur C, McGuinness S, Myburgh J, Norton R, Scheinkestel C, Su S (2009) Intensity of continuous renal-replacement therapy in critically ill patients. N Engl J Med 361:1627-1638

22. Palevsky PM, Zhang JH, O'Connor TZ, Chertow GM, Crowley ST, Choudhury D, Finkel K, Kellum JA, Paganini E, Schein RM, Smith MW, Swanson KM, Thompson BT, Vijayan A, Watnick S, Star RA, Peduzzi P (2008) Intensity of renal support in critically ill patients with acute kidney injury. N Engl J Med 359:7-20 
23. Vesconi S, Cruz DN, Fumagalli R, Kindgen-Milles D, Monti G, Marinho A, Mariano F, Formica M, Marchesi M, René R, Livigni S, Ronco C (2009) Delivered dose of renal replacement therapy and mortality in critically ill patients with acute kidney injury. Crit Care 13:R57-71

24. Joannes-Boyau O, Honoré PM, Perez P, Bagshaw SM, Grand H, Canivet JL, Dewitte A, Flamens C, Pujol W, Grandoulier AS, Fleureau C, Jacobs R, Broux C, Floch H, Branchard O, Franck S, Rozé H, Collin V, Boer W, Calderon J, Gauche B, Spapen HD, Janvier G, Ouattara A (2013) High-volume versus standard-volume haemofiltration for septic shock patients with acute kidney injury (IVOIRE study): a multicentre randomized controlled trial. Intensive Care Med 39:1535-1546

25. Sun Z, Ye H, Shen X, Chao H, Wu X, Yang J (2014) Continuous venovenous hemofiltration versus extended daily hemofiltration in patients with septic acute kidney injury: a retrospective cohort study. Crit Care 18:R70-79

26. Schwenger V, Weigand MA, Hoffmann O, Dikow R, Kihm LP, Seckinger J, Miftari N, Schaier M, Hofer S, Haar C, Nawroth PP, Zeier M, Martin E, Morath C (2012) Sustained low efficiency dialysis using a single- pass batch system in acute kidney injury - a randomized interventional trial: the Renal Replacement Therapy Study in Intensive Care Unit Patients. Crit Care 16:R140-149

27. Kielstein JT, Kretschmer U, Ernst T, Hafer C, Bahr MJ, Haller H, Fliser D (2004) Efficacy and Cardiovascular Tolerability of Extended Dialysis in Critically III Patients: A Randomized Controlled Study. Am J Kidney Dis 43:342349

28. Honoré PM, Jacobs R, Joannes-Boyau O, De Waele E, Van Gorp V, Boer W, Spapen HD (2013) Con: Dialy- and continuous renal replacement (CRRT) trauma during renal replacement therapy: still under-recognized but on the way to better diagnostic understanding and prevention. Nephrol Dial Transplant 28:2723-2728

29. Lee PA, Weger GW, Pryor RW, Matson JR (1998) Effects of filter pore size on efficacy of continuous arteriovenous hemofiltration therapy for Staphylococcus aureus-induced septicemia in immature swine. Crit Care Med 26:730737

30. Morgera S, Haase M, Kuss T, Vargas-Hein O, Zuckermann-Becker H, Melzer C, Krieg H, Wegner B, Bellomo R, Neumayer $\mathrm{HH}$ (2006) Pilot study on the effects of high cutoff hemofiltration on the need for norepinephrine in septic patients with acute renal failure. Crit Care Med 34:2099-2104

31. Morgera S, Haase M, Rocktäschel J, Böhler T, von Heymann C, Vargas-Hein O, Krausch D, Zuckermann-Becker H, Müller JM, Kox WJ, Neumayer HH (2003) High permeability haemofiltration improves peripheral blood mononuclear cell proliferation in septic patients with acute renal failure. Nephrol Dial Transplant 18:2570-2576

32. Shen HM, Pervaiz S (2006) TNF receptor superfamily-induced cell death: redox-dependent execution. FASEB J 20: 1589-1598

33. Bruewer M, Luegering A, Kucharzik T, Parkos CA, Madara JL, Hopkins AM, Nusrat A (2003) Proinflammatory cytokines disrupt epithelial barrier function by apoptosis-independent mechanisms. J Immunol 171:6164-6172

34. Han X, Fink MP, Uchiyama T, Yang R, Delude RL (2004) Increased iNOS activity is essential for pulmonary epithelial tight junction dysfunction in endotoxemic mice. Am J Physiol Lung Cell Mol Physiol 286:L259-L267

35. Ma TY, Iwamoto GK, Hoa NT, Akotia V, Pedram A, Boivin MA, Said HM (2004) TNF-alpha-induced increase in intestinal epithelial tight junction permeability requires NF-kB activation. Am J Physiol Gastrointest Liver Physiol 286:G367-G376

36. Coyne CB, Vanhook MK, Gambling TM, Carson JL, Boucher RC, Johnson LG (2002) Regulation of airway tight junctions by proinflammatory cytokines. Mol Biol Cell 13:3218-3234

37. Coopersmith CM, Stromberg PE, Dunne WM, Davis CG, Amiot DM 2nd, Buchman TG, Karl IE, Hotchkiss RS (2002) Inhibition of intestinal epithelial apoptosis and survival in a murine model of pneumonia-induced sepsis. JAMA 287:1716-1721

38. Guo S, Al-Sadi R, Said HM, Ma TY (2013) Lipopolysaccharide Causes an Increase in Intestinal Tight Junction Permeability in Vitro and in Vivo by Inducing Enterocyte Membrane Expression and Localization of TLR-4 and CD14. Am J Pathol 182:375-387

39. Sonnier DI, Bailey SR, Schuster RM, Gangidine MM, Lentsch AB, Pritts TA (2012) Proinflammatory chemokines in the intestinal lumen contribute to intestinal dysfunction during endotoxemia. Shock 37:63-69

40. Fink MP (2003) Intestinal epithelial hyperpermeability: update on the pathogenesis of gut mucosal barrier dysfunction in critical illness. Curr Opin Crit Care 9:143-151

\section{Submit your manuscript to a SpringerOpen ${ }^{\circ}$ journal and benefit from:}

- Convenient online submission

- Rigorous peer review

- Immediate publication on acceptance

- Open access: articles freely available online

- High visibility within the field

- Retaining the copyright to your article

Submit your next manuscript at $\boldsymbol{\nabla}$ springeropen.com 